\title{
Clinical spectrum of a-Gal syndrome: from immediate-type to delayed immediate-type reactions to mammalian innards and meat
}

Jörg Fischer', Amir S. YAZdi', TILo BiedermanN²

'Department of Dermatology, Allergy Unit Faculty of Medicine, Eberhard Karls University, Tuebingen, Germany; 2Department of Dermatology and Allergy Biederstein, Technical University Munich, Germany

\begin{abstract}
The term $\alpha$-Gal syndrome describes a novel IgE-mediated immediate-type allergy to the disaccharide galactose- $\alpha-1,3$-galactose ( $\alpha$-Gal). Its classification as a syndrome is proposed on the basis of its clinical relevance in three different fields of allergy: food, drugs, and tick bites. The main focus of the present article is on $\alpha-\mathrm{Gal}$ as an eliciting allergen in food allergy. It was recently shown that immediate-type allergies to pork kidney and other mammalian innards belong to the spectrum of $\alpha-G a l$ syndrome. These allergic reactions manifest as classic immediate-type allergies with a typical latency of under $1 \mathrm{~h}$. The phenomenon of a delayed-onset immediatetype allergy with a latency of 3-6 $\mathrm{h}$ following ingestion of mammalian meat is considered pathogno-
\end{abstract}

monic for $\alpha-G a l$ syndrome. This clinically distinct type of presentation can be explained using the concept of food-dependent exercise-induced anaphylaxis (FDEIA). However, clinical observations and challenge testing in this constellation reveal that individual sensitivity in $\alpha$-Gal patients is highly variable and which broadens our basic understanding of $\alpha$-Gal syndrome.

Cite this as Fischer J, Yazdi AS, Biedermann T. Clinical spectrum of $a-$ Gal syndrome: from immediate-type to delayed immediate-type reactions to mammalian innards and meat. Allergo J Int 2016;25: $55-62$

DOI: $10.1007 / s 40629-016-0099-z$

\section{Introduction}

The identification of immunoglobulin E (IgE)-mediated immediate-type reactions to the disaccharide galactose- $\alpha-1,3$-galactose ( $\alpha$-Gal) fundamentally altered our understanding of the allergenic potential of carbohydrate structures and formed the starting point for further discoveries in the area of immediate-type allergy [1]. $\alpha-\mathrm{Gal}$ is a typical component of glycoproteins in mammals. However, in

Abbrevations
$\begin{array}{ll}\text { a-Gal } & \text { Galactose-a-1,3-galactose } \\ \text { EGFR } & \text { Epidermal growth factor receptor } \\ \text { FDEIA } & \text { Food-dependent exercise-induced anaphy- } \\ & \text { laxis } \\ \text { IgE } & \text { Immunoglobulin } \mathrm{E} \\ \text { tlgE } & \text { Total lgE }\end{array}$

\section{Key words}

Galactose- $a-1,3-$

galactose $-a-G a l$ syndrome -

Cetuximab - Pork kidney - Red meat

\section{Submitted}

July 14, 2015

\section{Accepted}

September 21, 2015

German Version www.springermedizin.de/ allergo-journal 
the course of evolution, primates and humans have lost the enzyme required for $\alpha-\mathrm{Gal}$ production, galactosyltransferase [2]. As a result, this disaccharide is immunogenic in humans [2]. a-Gal syndrome was recently proposed as a new term to better describe this novel disease that occurs worldwide $[2,3]$. The term $\alpha$-Gal syndrome is clinically defined by three facets of this allergy (Fig. 1): Firstly, as a food allergy with type-I allergic reactions of typically delayed onset following the ingestion of mammalian meat and innards [4]; secondly, as drug allergy, particularly in the case of parenteral administration of drugs obtained from cells or tissue from mammals (e.g., cetuximab or gelatin-based colloids) $[1,5]$; and thirdly, by allergic reactions to tick bites [6]. Local allergic reactions to tick bites are regularly reported on a global basis $[6,7,8]$. Reports of the regular occurrence of anaphylaxis due to techniques used to remove adult ticks of the Ixodes holocyclus species from the host are restricted to Australia [7]. According to the current state of knowledge, tick bites are ascribed a central role in the development of type-I sensitization to $\alpha-\mathrm{Gal}$ [7]. The aim of the present article is to outline the clinical spectrum of a-Gal-related food allergy and demonstrate how geographically local phenomena may be helpful in our understanding of this complex disease.

\section{a-Gal syndrome}

\section{Drug allergy}

Drugs derived from mammalian cells and tissue
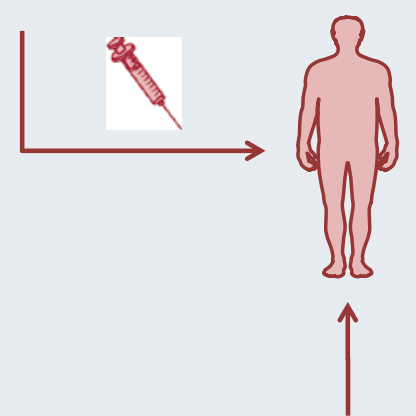

Tick bite allergy

Currently favored pathway of IgE sensitization to a-Gal

Fig. 1: The term a-Gal syndrome describes a novel lgE-mediated immediatetype allergy to the disaccharide galactose- $a-1,3-$ galactose ( $a-G a l)$ as an allergen. Its classification as a syndrome was proposed on the basis that it is clinically relevant in three different fields of allergy: food, drugs, and tick bites.

\section{Discovery and symptoms of a-Gal syndrome in Germany}

The story of $\alpha-G a l$ in Germany and France begins with immediate-type allergies following the consumption of pork kidney. Although immediate-type reactions following the ingestion of kidney are globally rare, their occurrence in Europe is nonetheless so frequent as to be recognized as a phenomenon by European physicians active in the field of allergology $[9,10,11]$. The reason behind this is that innards are consumed as local delicacies in many regions of $\mathrm{Eu}$ rope, as well as being used in sausage products. Kidney, tripe, heart, sweetbread, lungs, brain, and tongue from pork, beef, and lamb are processed in such delicacies and consumed. The partially higher content in terms of cholesterol, vitamin A, purines, enriched toxic substances, as well as a higher susceptibility to spoilage have lead in recent years to a discussion on the consumption of innards. One only has to look at restaurant menus to see that demand in the population for innards is on the decline. A recent epidemiological study conducted by our working group in southern Germany also sampled participants on their attitude to the consumption of innards. Of 845 participants, $96.8 \%$ stated that they had eaten beef or pork in the previous 12 months. Of these subjects, $53.4 \%$ had consumed beef or pork innards at least once. Innards are consumed more frequently by men compared with women $(62.8 \%$ vs. $40.2 \%)$ and more frequently by older adults $(>60$ years) compared with children or young adults $(<20$ years) $(66.4 \%$ vs. $25.8 \%)$ (unpublished data). This study shows that the consumption of innards remains widespread and is practiced in all age groups. One can assume that cultural eating habits are reflected in the prevalence of allergic reactions to innards. Interestingly individuals allergic to kidney consumed pork/beef meat regularly and reported to have tolerated these well. Therefore a cross reaction between muscle meat and innards was not initially assumed. Unknown kidney-specific proteins, as well as pseudo-allergenic substances that accumulate in the kidneys as an excretory organ, were discussed as possible triggers of these immediate-type reactions to kidney. In 2005, the working group lead by Dr. Jappe began collecting cases of immediate-type allergy following consumption of pork kidney, with the aim of identifying the eliciting allergen $[12,13]$. Based on a patient with coincidental anaphylaxis to cetuximab, Dr. Jappe was the first German allergologist to recognize and follow-up an association between immediate-type allergy to pork kidney and the a-Gal sensitization first described in the US. She developed a Western blot using cetuximab as an a-Gal-bearing target structure to detect specific IgE antibodies to $\alpha-G a l$ [14]. Between 2008 and 2011, 32 patients with allergic reactions to mammalian meat 
and/or kidney and other innards were identified in Germany [15]. IgE sensitization to $\alpha$-Gal was detected in $79 \%$ of these patients using Western blot and in $88 \%$ using experimental ImmunoCAP ${ }^{\circledR}$ tests. This case study collection also showed that, contrary to expert opinion, a number of the affected patients developed allergic reactions not only after consuming pork kidney, but also following mammalian meat. Initially, however, an explanation for this phenomenon remained elusive. The delayed onset of systemic allergic reactions, with a 3- to 6-h latency between consumption and manifestation of the reaction, was considered pathognomonic for $\alpha$-Galrelated meat allergy. In contrast, systemic allergic reactions/anaphylaxis following the consumption of pork kidney typically manifested as classic immediate-type allergies within $1 \mathrm{~h}$. In 2012, the French allergologist Dr. Morisset published a series of cases of 14 patients with anaphylaxis following the consumption of pork kidney [16]. Using CAP inhibition testing, she demonstrated that pork kidney contains quantitatively more $\alpha$-Gal compared to pork meat. Based on a careful analysis of the patient histories, she put forward the concept of food-dependent exercise-induced anaphylaxis (FDEIA) to explain the unexpected difference in temporal dynamics of the reaction. The relevance of these co- or augmentation factors in the elicitation of an immediate-type systemic allergic reaction is enjoying ever greater general acceptance in allergology, despite the fact that the precise underlying mechanisms remain the subject of research [17]. Exactly how $\alpha-\mathrm{Gal}$ is absorbed is not yet clear. It is assumed, however, that lipid and glycolipid digestion plays a crucial role [18]. This digestion process can be quantitatively and kinetically modulated by individual, or a combination of exogenous and endogenous factors (e.g., physical exercise, alcohol, non-steroidal analgesics, infections, menstruation). According to the concept of FDEIA, these cofactors are assigned the key role until modulating intestinal absorption of a food allergen in the body a critical allergen concentration capable of eliciting an allergic reaction is reached.

In January 2012 the introduction of a specific IgE test - initially limited to scientific applications - using bovine thyroglobulin as an $\alpha$-Gal-bearing target structure simplified the diagnosis of $\alpha$-Gal syndrome significantly. By Spring 2015, we had diagnosed $a-G a l$ syndrome in 55 patients (Tab. 1). If one estimates the prevalence of $\alpha$-Gal syndrome in this pilot region using the Australian example as a guidance, one can assume a prevalence of at least four cases per 100,000 inhabitants in Baden-Württemberg, Germany (Virginia, USA: 13 cases/100,000 inhabitants; New South Wales, Australia: 113 cases/100,000 inhabitants) [7]. The German patients were aged between 27 and 83 years (median 59 years) at the time of first diagnosis. The current patient cohort consists of more men than women (female to male ratio, $1: 1.75$ ) (Tab. 1). In contrast to the US, there have been no conclusive cases of a-Gal syndrome in children or adolescents in Germany as yet [19]. The children and adolescents known to us to have allergic reactions to meat have hitherto been diagnosed with other meat allergy entities (e.g. pork-cat syndrome, beef-milk syndrome, or poultry meat allergy) [20, 21, 22]. According to their patient histories, $65.5 \%$ of adult a-Gal syndrome patients had experienced dangerous systemic allergic reactions on at least one occasion (anaphylaxis > II according to Ring/Messmer), and $34.5 \%$ urticaria/angioedema (anaphylaxis I according to Ring/Messmer) [23]. Against the backdrop of reactions at short intervals, the diagnosis of chronic urticaria or idiopathic angioedema was incorrectly made in seven patients. Allergic reactions to mammalian meat only were reported by $43.6 \%$ of $\alpha-\mathrm{Gal}$ syndrome patients. These patients stated that they had never knowingly consumed innards. In some of these cases, reactions occurred following consumption of sausage products containing an unknown proportion of innards. Reactions were most frequently reported after ingesting beef $(53 \%)$ and pork (47\%), less often after lamb $(9.1 \%)$ or deer $(7.3 \%)$. Of the $a-G a l$ syndrome patients, $29.1 \%$ reported systemic allergic reactions after consuming both mammalian meat and pork kidney. Two of these patients had also experienced reactions to other innards (tripe, lung, heart) in their histories. A typical feature in this patient group was that reactions were seen with a time delay of 3-6 h when muscle meat was consumed, whereas reactions occurred within as little as $1 \mathrm{~h}$ following the consumption of pork kidney $[16,24]$. Reactions following the consumption of pork kidney were reported by $27.3 \%$ of $\alpha$-Gal syndrome patients. The fact that mammalian meat was consumed regularly and had never caused allergic reactions, even when evaluated over long periods, was also typical for this patient group [24]. Allergic reactions in these patients with no additional allergy to muscle meat typically occurred with a time delay of 3-6 h after consuming pork kidney. Milk products such as milk, cream, and cheese were tolerated by the patients known to us. One highly sensitized patient exhibited an a-Gal-dependent immediate-type reaction after consuming a large quantity of gelatin-containing sweets (e.g., gummy bears) [25]. Adverse events following the infusion of $\alpha$-Gal-containing drugs (e.g., cetuximab or gelatin-based colloids) have also been observed in southern Germany; however, due to a lack of data, it has not been possible to assess their frequency as yet. We are also aware of one fatality due to 
Tab. 1. Clinical characteristics of 55 German patients with a-Gal syndrome. Patients with a history of allergic reactions following consumption of pork kidney $(n=25)$ have already been published in a case collection [24]

\begin{tabular}{|c|c|c|c|c|c|c|c|c|c|c|}
\hline $\begin{array}{l}\text { Patient } \\
\text { no. }\end{array}$ & Age & Sex & $\begin{array}{l}\text { Anaphylaxis* } \\
\text { (Ring/Messmer } \\
{[23] \text { ) }}\end{array}$ & $\begin{array}{l}\text { Meat } \\
\text { allergy }\end{array}$ & Type & $\begin{array}{l}\text { Delay } \\
\text { (h) }\end{array}$ & $\begin{array}{l}\text { Pork kidney } \\
\text { allergy }\end{array}$ & $\begin{array}{l}\text { Delay } \\
\text { (h) }\end{array}$ & $\begin{array}{l}\text { a-Gal } \\
\left(\mathrm{kU}_{\mathrm{A}} / \mathrm{l}\right)\end{array}$ & $\begin{array}{l}\operatorname{tgE} \\
\left(\mathrm{kU}_{\mathrm{A}} / \mathrm{l}\right)\end{array}$ \\
\hline 1 & 62 & $M$ & Grade 3 & no & & & yes & $1-3$ & n.a. & 203 \\
\hline 2 & 76 & M & Grade 2 & no & & & yes & $>3$ & 48.5 & n.a. \\
\hline 3 & 35 & $M$ & Grade 1 & yes & Beef, pork & & n.a. & & n.a. & 103 \\
\hline 4 & 56 & M & Grade 1 & no & & & yes & $>3$ & 3.12 & 144 \\
\hline 5 & 70 & $F$ & Grade 3 & no & & & yes & $>3$ & 2.87 & 42.2 \\
\hline 6 & 50 & $\mathrm{~F}$ & Grade 2 & no & & & yes & $>3$ & 15.4 & 257 \\
\hline 7 & 66 & $F$ & Grade 2 & yes & Beef, pork & $1-3$ & yes & $<1$ & 18.9 & 157 \\
\hline 8 & 66 & M & Grade 3 & yes & Pork & $>3$ & yes & $<1$ & 60.1 & 761 \\
\hline 9 & 53 & M & Grade 2 & no & & & yes & $<1$ & 1.22 & 38.2 \\
\hline 10 & 50 & M & Grade 1 & yes & Beef & $1-3$ & n.a. & & 60.7 & 434 \\
\hline 11 & 55 & M & Grade 3 & yes & Beef, pork & $>3$ & yes & $>3$ & 9.13 & 116 \\
\hline 12 & 32 & $M$ & Grade 2 & no & & & yes & $1-3$ & 15.5 & 167 \\
\hline 13 & 65 & $F$ & Grade 3 & yes & Lamb & $>3$ & yes & $1-3$ & 9.18 & 74.5 \\
\hline 14 & 40 & $\mathrm{~F}$ & Grade 3 & yes & Pork & $>3$ & yes & $<1$ & 84.1 & 955 \\
\hline 15 & 57 & $F$ & Grade 2 & yes & Pork & $>3$ & yes & & 65.9 & 148 \\
\hline 16 & 47 & M & Grade 2 & yes & Beef, pork, deer & $>3$ & yes & $<1$ & 69.3 & 594 \\
\hline 17 & 69 & M & Grade 3 & yes & Pork & $>3$ & n. a. & & 26.9 & 334 \\
\hline 18 & 73 & M & Grade 2 & yes & Pork & $>3$ & yes & $1-3$ & 11.8 & 46.6 \\
\hline 19 & 70 & M & Grade 3 & yes & Beef, pork & $>3$ & n. a. & & 3.9 & 149 \\
\hline 20 & 53 & M & Grade 1 & no & & & yes & & 1.56 & 74.9 \\
\hline 21 & 60 & $\mathrm{~F}$ & Grade 2 & yes & Beef, pork & & n. a. & & 1.5 & 280 \\
\hline 22 & 57 & M & Grade 1 & yes & Pork & $>3$ & n. a. & & 0.72 & 730 \\
\hline 23 & 78 & M & Grade 3 & no & & & yes & $<1$ & 41 & 384 \\
\hline 24 & 28 & M & Grade 1 & yes & Beef, pork & & n. a. & & 1.8 & 342 \\
\hline 25 & 59 & M & Grade 1 & yes & $\begin{array}{l}\text { Beef, pork, lamb, } \\
\text { deer }\end{array}$ & $>3$ & n. a. & & 16.3 & 104 \\
\hline 26 & 73 & $\mathrm{~F}$ & Grade 2 & yes & Beef, pork & $>3$ & yes & $>3$ & 11.9 & 163 \\
\hline 27 & 71 & M & Grade 3 & yes & Beef & & n.a. & & 0.55 & 181 \\
\hline 28 & 44 & $\mathrm{~F}$ & Grade 1 & yes & Beef, pork & $>3$ & n.a. & & 43.3 & 132 \\
\hline 29 & 57 & M & Grade 2 & yes & Beef, pork & $>3$ & yes & $<1$ & 45.6 & 401 \\
\hline 30 & 66 & $\mathrm{~F}$ & Grade 2 & yes & Beef, pork & & yes & & 0.12 & 10.4 \\
\hline 31 & 63 & $\mathrm{~F}$ & Grade 2 & yes & Beef, pork, lamb & $>3$ & yes & $<1$ & 2.11099 & 1.099 \\
\hline 32 & 38 & M & Grade 2 & yes & Beef, pork & & n.a. & & 73 & 134 \\
\hline 33 & 66 & $\mathrm{~F}$ & Grade 1 & yes & Beef, pork & & n.a. & & 0.67 & 7.8 \\
\hline 34 & 55 & M & Grade 2 & no & & $>3$ & yes & $>3$ & 13.2 & 29.9 \\
\hline
\end{tabular}




\begin{tabular}{|c|c|c|c|c|c|c|c|c|c|c|}
\hline Patient no. & Age & Sex & $\begin{array}{l}\text { Anaphylaxis* } \\
\text { (Ring/Messmer } \\
{[23] \text { ) }}\end{array}$ & $\begin{array}{l}\text { Meat } \\
\text { allergy }\end{array}$ & Type & $\begin{array}{l}\text { Delay } \\
\text { (h) }\end{array}$ & $\begin{array}{l}\text { Pork kidney } \\
\text { allergy }\end{array}$ & $\begin{array}{l}\text { Delay } \\
\text { (h) }\end{array}$ & $\begin{array}{l}\text { a-Gal } \\
\left(\mathrm{kU}_{\mathrm{A}} / \mathrm{l}\right)\end{array}$ & $\begin{array}{l}\operatorname{tg}{ }^{\prime} \\
\left(\mathrm{kU}_{\mathrm{A}} / \mathrm{l}\right)\end{array}$ \\
\hline 35 & 71 & M & Grade 2 & yes & Beef, pork, deer & & yes & & 230 & 507 \\
\hline 36 & 61 & M & Grade 2 & yes & Beef & $>3$ & yes & & 67.6 & 419 \\
\hline 37 & 55 & M & Grade 3 & yes & Pork & & n. a. & & 2.8 & 255 \\
\hline 38 & 43 & $\mathrm{~F}$ & Grade 2 & no & & & yes & & 3.5 & 59.2 \\
\hline 39 & 52 & M & Grade 2 & no & & & yes & $<1$ & 9.3 & 106 \\
\hline 40 & 50 & M & Grade 1 & no & & & yes & & 0.75 & 72.8 \\
\hline 41 & 73 & M & Grade 1 & no & & & yes & & 3.5 & 72.9 \\
\hline 42 & 57 & M & Grade 2 & yes & Beef, lamb & $>3$ & n. a. & & 19.3 & 114 \\
\hline 43 & 66 & $\mathrm{~F}$ & Grade 2 & yes & Beef, pork & & yes & $<1$ & 63.3 & 2834 \\
\hline 44 & 71 & M & Grade 2 & no & & & yes & $>3$ & 18.4 & 137 \\
\hline 45 & 34 & M & Grade 1 & yes & Pork & $>3$ & n. a. & & 23.4 & 56.6 \\
\hline 46 & 63 & $\mathrm{~F}$ & Grade 1 & yes & Pork & & n. a. & & 3.2 & 104 \\
\hline 47 & 75 & $\mathrm{~F}$ & Grade 1 & yes & Pork & & n. a. & & 1.2 & 260 \\
\hline 48 & 69 & $\mathrm{~F}$ & Grade 1 & yes & Beef & $>3$ & n. a. & & 85.7 & 252 \\
\hline 49 & 74 & M & Grade 3 & yes & Beef & $>3$ & yes & $<1$ & 55.1 & 200 \\
\hline 50 & 69 & $\mathrm{~F}$ & Grade 1 & yes & Pork & $>3$ & n. a. & & 180 & 983 \\
\hline 51 & 36 & M & Grade 2 & yes & Beef, pork & $>3$ & n. a. & & 20.7 & 402 \\
\hline 52 & 47 & M & Grade 3 & yes & Beef, pork & $>3$ & n. a. & & 9.4 & 70.1 \\
\hline 53 & 84 & $\mathrm{~F}$ & Grade 1 & yes & Deer & $>3$ & n. a. & & 7.3 & 116 \\
\hline 54 & 51 & M & Grade 1 & yes & Lamb & $>3$ & n. a. & & 91.9 & 587 \\
\hline 55 & 66 & M & Grade 1 & yes & Beef, pork & $>3$ & n. a. & & 15.1 & 2465 \\
\hline
\end{tabular}

anaphylaxis upon initial administration of cetuximab.

\section{Diagnostic workup and risk management of a-Gal syndrome in Germany}

Since prick test solutions that are authorized and available in Germany show very low sensitivity in a-Gal-allergic patients, they confer no diagnostic benefit. Unfortunately, intradermal tests for meat have not been available in Germany since 2007; indeed, no officially authorized test allergens for intradermal testing for foodstuffs have been avail- able since autumn 2014 anymore. Using older case studies in Germany as a guide, one can assume that intradermal testing with meat extracts would provide a sensitive diagnostic workup $[9,26]$. Prick-toprick tests using fresh meat and kidney preparations offer a remedy here. The use in particular of pork or beef kidney proved to be more sensitive in the prick-to-prick test compared with muscle meat from the respective species. An intradermal test with $4 \%$ gelatin polysuccinate (Gelafundin) is easier to perform compared with fresh meat and kidney preparations and offers comparable sensitivity 


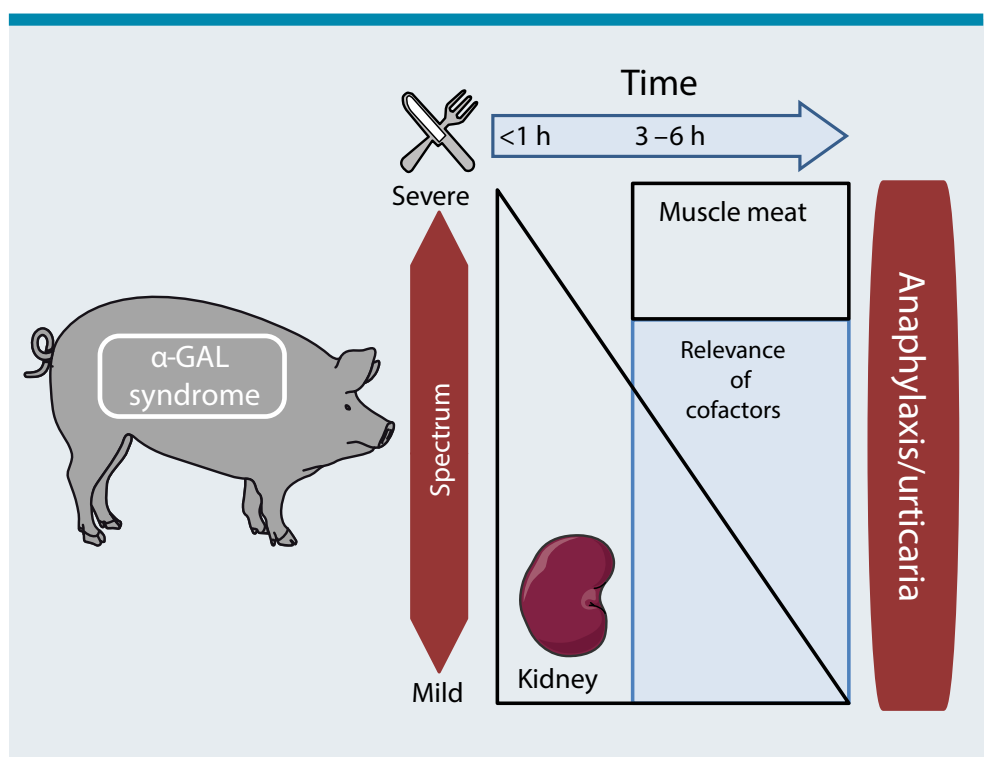

Fig. 2: The individual sensitivity of patients with a-Gal syndrome varies. Patients with greater sensitivity react with delayed type-1 reactions following consumption of mammalian meat. Consuming kidney from the same mammalian species can trigger allergic reactions earlier. Moderate sensitivity is characterized by the fact that a type-I allergy only occurs in the presence of co- or augmentation factors (e. g., physical exercise, analgesics, or alcohol). When kidney is consumed, type-I reactions can also occur without cofactors. In the case of low sensitivity, muscle meat is not capable of triggering reactions in a-Gal syndrome patients. However, these patients may react following the consumption of kidney with a delay of 3-6 h.

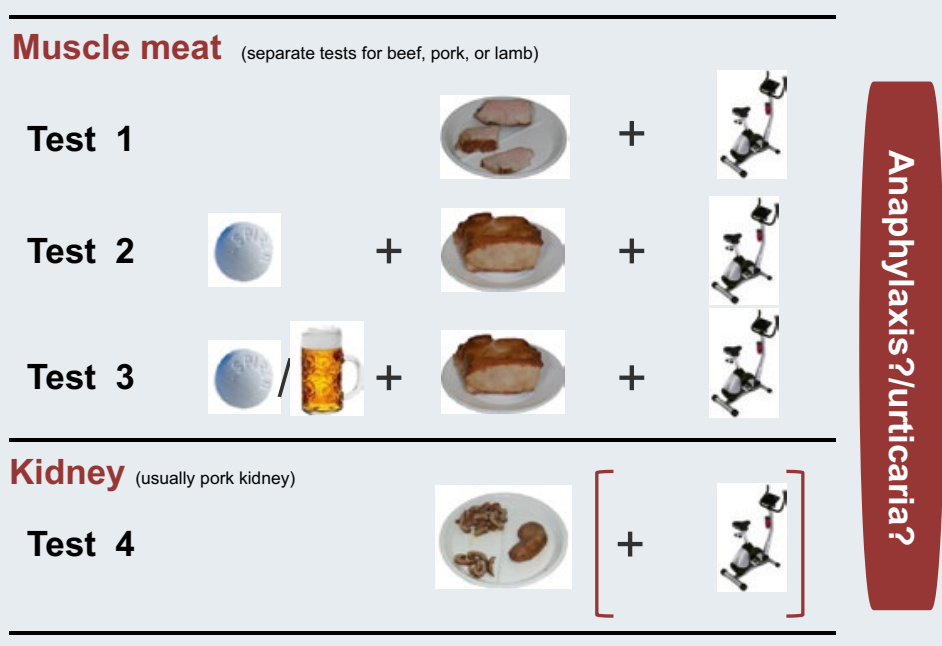

Fig. 3: Established challenge testing sequence to determine individual sensitivity in a-Gal syndrome. Oral challenge tests are performed on an inpatient basis with emergency response measures in place. Cofactors include $1,000 \mathrm{mg}$ acetylsalicylic acid, plus additional alcohol (maximum $500 \mathrm{ml}$ beer or $250 \mathrm{ml}$ wine) $1 \mathrm{~h}$ prior to meat consumption, as well as a 20-min training session on a bike ergometer $1 \mathrm{~h}$ following consumption.
[24]. However, here again, the discontinuation of standardized positive controls for intradermal testing makes this diagnostic approach more challenging. Therefore, measuring specific serum IgE to $a-G a l$ represents the most important diagnostic tool. A CE-certified test allergen has been available to this end since June 2015.

Oral challenge testing is useful to assess the clinical relevance of a type-I sensitization to $\alpha-\mathrm{Gal}$, as well as in individual allergologic dietary counseling. Since challenge tests are difficult to control due to the delayed onset of reactions, these tests should be performed by experienced allergists on an inpatient basis with emergency response measures in place. Sensitivity to $\alpha-G a l$ in mammalian innards or meat is subject to variation (Fig. 2). Standardized challenge tests confirmed that combining cofactors (primarily physical exercise, alcohol, non-steroidal anti-inflammatory drugs) in the testing process may be necessary in order to trigger an allergic reaction following meat consumption [24] (Fig. 3). However, according to own experience to date, exposure to muscle meat elicits a systemic allergic reaction in only $30 \%$ of a-Gal-syndrome patients even when cofactors are included. Exposure to pork kidney without cofactors triggered systemic allergic reactions in $78 \%$ of exposed patients at our hospital. These observations support findings from France that kidney contains a higher concentration of $\alpha-G a l$ compared with muscle meat, and that digestion involving more rapid release and/or intestinal absorption of $\alpha-\mathrm{Gal}$ from innards is possible [18].

All $\alpha$-Gal-syndrome patients are prescribed an allergy emergency kit, comprising an adrenaline auto-injector, oral antihistamine, and corticosteroids, and issued with an anaphylaxis identification card [25]. This anaphylaxis identification card includes a warning about the use of $\alpha$-Gal-containing drugs. Cetuximab and gelatin-derived colloids are proven to be hazardous [27]. The human antibody panitumumab, which also targets the epidermal growth factor receptor (EGFR), can be used instead of cetuximab in chemotherapy-refractory metastatic malignancy, such as head and neck or colorectal cancer [28]. Follow-up observations to date have shown that only a small number of affected individuals adopt a vegetarian diet following diagnosis. Most $\alpha$-Gal-syndrome patients successfully prevent recurrent episodes of anaphylaxis by reducing the quantity of meat they consume and by eating more $\alpha$-Gal-free poultry as a substitute. Observations of individual patients in $\mathrm{Mu}$ nich and Tübingen have yielded evidence that complete avoidance can potentially result in anaphylaxis to even tiny quantities of meat, thereby pointing to possible mechanisms of oral tolerance 
(personal communication, F. Rueff; follow-up case study [25]).

\section{Prevalence of type-I sensitization to $a-G a l$ in Germany}

Recent epidemiological studies put the prevalence of $\alpha$-Gal sensitization [as measured by positive $\operatorname{sIgE}\left(>0.1 \mathrm{kU}_{\mathrm{A}} / \mathrm{l}\right)$ to $\left.\alpha-\mathrm{Gal}\right]$ in Europe at $5.5 \%-8.1 \%$ [29], whereby it is assumed that sensitization rates vary considerably from region to region. Over the last 2 years, studies on the prevalence of $\alpha-G a l$ syndrome have been carried out with the support of the Baden-Württemberg State Health Office. The studies concentrated on Tübingen, Reutlingen, Böblingen, Esslingen, and Stuttgart, all districts located around the Schönbuch nature park. Investigations began with hunters and foresters, subsequently extending to the general populations of these districts. Analysis of the data is still ongoing. However, a distinctly higher prevalence can be seen for this area compared with the prevalence published for Europe to date. Sensitizations are also seen as frequently in children as in adults. An association with tick bites is assumed. Pronounced local reactions lasting between 14 days and several weeks at the site of bites from the Ixodes ricinus tick have been observed in $\alpha$-Gal-sensitized individuals in southern Germany [30]. Since tick bites are usually only associated with infections (primarily Lyme disease and tick-borne encephalitis), affected individuals tend not to spontaneously report local reactions of this kind. Anaphylaxis upon tick removal, as observed in Australia, has not been reported in southern Germany [7]. The comparatively high prevalence seen in southern Germany underlines the medical need for oral challenge testing to assess the clinical relevance of type-I sensitization to $a-G a l$ in terms of mammalian meat consumption.

\section{Conclusion}

Demonstrating that muscle meat and innards are a source (of varying potency) of allergic reactions in $\alpha-G a l$ syndrome represents an important European contribution to the understanding of $\alpha-\mathrm{Gal}$ syndrome. Pork innards elicit the highest rate of reactions in challenge tests in $\alpha$-Gal-syndrome patients. It has been demonstrated that the concept of FDEIA is important in the clinical picture of a-Gal syndrome $[16,24]$. This also explains why the consumption of meat does not always elicit allergic reactions in affected patients. European observations also reveal that there are $\alpha$-Gal-syndrome patients with extremely high triggering thresholds that can only be reached in daily life by consuming pork kidneys with/without cofactors. This makes it more challenging to assess the indi- vidual risk of type-I $a-$ Gal sensitization for patients and underlines the medical benefit of oral challenge testing.

\section{Jörg Fischer, MD}

Department of Dermatology

Faculty of Medicine

Eberhard Karls University Tuebingen

Liebermeisterstraße 25

72076 Tuebingen, Germany

E-Mail: joerg.fischer@med.uni-tuebingen.de

\section{Conflict of interest}

The authors declare that there are no conflicts of interest.

\section{Cite this as}

Fischer J, Yazdi AS, Biedermann T. Clinical spectrum of a-Gal syndrome: from immediate-type to delayed immediate-type reactions to mammalian innards and meat. Allergo J Int 2016;25:55-62

DOI: $10.1007 /$ s40629-016-0099-z

\section{References}

1. Chung CH, Mirakhur B, Chan E, Le QT, Berlin J, Morse M et al. Cetuximab-induced anaphylaxis and $\lg E$ specific for galactose-alpha-1,3-galactose. N Engl J Med 2008:358:1109-17

2. Platts-Mills TA, Schuyler AJ, Hoyt AE, Commins SP. Delayed anaphylaxis involving IgE to galactose-alpha-1,3-galactose. Curr Allergy Asthma Rep 2015;15:12

3. Steinke JW, Platts-Mills TA, Commins SP. The alpha-gal story: lessons learned from connecting the dots. J Allergy Clin Immunol 2015;135:589-96

4. Commins SP, Satinover SM, Hosen J, Mozena J, Borish L, Lewis BD et al. Delayed anaphylaxis, angioedema, or urticaria after consumption of red meat in patients with $\lg \mathrm{E}$ antibodies specific for galactose-alpha-1,3-galactose. J Allergy Clin Immunol 2009;123:426-33

5. Mullins RJ, James H, Platts-Mills TA, Commins S. Relationship between red meat allergy and sensitization to gelatin and galactose- $a-1,3-$ galactose. J Allergy Clin Immunol 2012;129:1334-42

6. Commins SP, James HR, Kelly LA, Pochan SL, Workman LJ, Perzanowski MS et al. The relevance of tick bites to the production of IgE antibodies to the mammalian oligosaccharide galactose-a-1,3-galactose. J Allergy Clin Immunol 2011;127:1286-93

7. Nunen S van. Tick-induced allergies: mammalian meat allergy, tick anaphylaxis and their significance. Asia Pac Allergy 2015;5:3-16

8. Hamsten C, Starkhammar M, Tran TA, Johansson M, Bengtsson $U$, Ahlén $G$ et al. Identification of galactose- $a-1,3$-galactose in the gastrointestinal tract of the tick Ixodes ricinus; possible relationship with red meat allergy. Allergy 2013;68:549-52

9. Biedermann T, Röcken M. Verzögert auftretende Symptome einer Soforttypallergie: Typ-I-Sensibilisierung gegenüber Galaktose-a-1,3-Galaktose. Hautarzt 2012;63 (Suppl 1):76-9

10. Llátser R, Polo F, De La Hoz F, Guillaumet B. Alimentary allergy to pork. Crossreactivity among pork kidney and pork and lamb gut. Clin Exp Allergy 1998;28:1021-5

11. Jacquenet $S$, Moneret-Vautrin DA, Bihain BE. Mammalian meat-induced anaphylaxis: clinical relevance of anti-galactose-alpha-1,3-galactose IgE confirmed by means of skin tests to cetuximab. J Allergy Clin Immunol 2009;124:603-5 
12. Jappe U, Kreft B, Ludwig A, Przybilla B, Walker A, Becker WM et al. Allergy to red meat/innards is associated with IgE to a new mammalian cross-reactive carbohydrate determinant also found in Cetuximab and cat IgA. Session: Highlights in Molecular Allergology. Abstracts of the XXIX EAACI Congress of the European Academy of Allergy and Clinical Immunology, London, UK, 5-9 June 2010. Allergy 2010;65 (Suppl 92):164-5

13. Jappe U, Kreft B, Ludwig A, Przybilla B, Walker A, Biedermann $T$ et al. IgE-reactivity to a new mammalian cross-reactive carbohydrate determinant (alpha-GAL): relevance for drug as well as food allergy. New Trends in Allergy, Munich, 22-24 July 2010. Allergo J 2010;19:332

14. Jappe U, Kreft B, Ludwig A. Aufbau und Anwendung eines sensitiven Verfahrens zum Nachweis von IgEAntikörpern gegen das Kohlenhydratepitop Galaktose-alpha-1,3-Galaktose. Meeting Abstract. 6. Deutscher Allergie-Kongress, Wiesbaden 2011. Allergo J 2011;20:33

15. Jappe U, Platts-Mills T, Przybilla B, Kreft B, Ludwig A, Walker $A$ et al. IgE-reactivity to galactose-a-1,3-galactose: a prospective multicenter study on meat allergy, urticaria and anaphylaxis. XXXI Congress of the European Academy of Allergy and Clinical Immunology Abstract Book, Geneva, Switzerland, 16-20 June 2012. Allergy 2012;67(Suppl 96):96

16. Morisset M, Richard C, Astier C, Jacquenet S, Croizier A Beaudouin $E$ et al. Anaphylaxis to pork kidney is related to IgE antibodies specific for galactose-alpha-1,3-galactose. Allergy 2012;67:699-704

17. Wölbing F, Fischer J, Köberle M, Kaesler S, Biedermann T. About the role and underlying mechanisms of cofactors in anaphylaxis. Allergy 2013;68:1085-92

18. Commins SP, Platts-Mills TA. Allergenicity of carbohydrates and their role in anaphylactic events. Curr Allergy Asthma Rep 2010;10:29-33

19. Kennedy JL, Stallings AP, Platts-Mills TA, Oliveira WM, Workman L, James HR et al. Galactose- $\mathbf{a}-1,3-$ galactose and delayed anaphylaxis, angioedema, and urticaria in children. Pediatrics 2013;131:1545-52
20. Werfel SJ, Cooke SK, Sampson HA. Clinical reactivity to beef in children allergic to cow's milk. J Allergy Clin Immunol 1997;99:293-300

21. Posthumus J, James HR, Lane CJ, Matos LA, Platts-Mills TA, Commins SP. Initial description of pork-cat syndrome in the United States. J Allergy Clin Immunol 2013;131:923-5

22. González-Mancebo E, Pastor C, González-de-Olano D, Gandolfo-Cano M, Melendez A, Cuesta J et al. Identification of allergens in chicken meat allergy. J Investig Allergol Clin Immunol 2011;21:326-7

23. Ring J, Messmer K. Incidence and severity of anaphylactoid reactions to colloid volume substitutes. Lancet 1977;1:466-9

24. Fischer J, Hebsaker J, Caponetto P, Platts-Mills TA, Biedermann T. Galactose-alpha-1,3-galactose sensitization is a prerequisite for pork-kidney allergy and cofactor-related mammalian meat anaphylaxis. J Allergy Clin Immunol 2014;134:755-9

25. Caponetto P, Fischer J, Biedermann T. Gelatin-containing sweets can elicit anaphylaxis in a patient with sensitization to galactose-a-1,3-galactose. J Allergy Clin Immunol Pract 2013;1:302-3

26. Fischer J, Yazdi A, Biedermann T. Mammalian meat allergy: a diagnostic challenge. Allergo J Int 2015;24:81-3

27. Pointreau Y, Commins SP, Calais G, Watier H, Platts-Mills TA. Fatal infusion reactions to cetuximab: role of immunoglobulin e-mediated anaphylaxis. J Clin Oncol 2012;30:334

28. Caponetto P, Biedermann T, Yazdi A, Fischer J. Panitumumab: a safe option for oncologic patients sensitized to galactose-a-1,3-galactose J Allergy Clin Immunol Pract 2015; pii: S2213-2198(15)00319-0. doi: 10.1016/j.jaip.2015.06.015

29. Gonzalez-Quintela A, Dam Laursen AS, Vidal C, Skaaby T, Gude F, Linneberg A. IgE antibodies to alpha-gal in the general adult population: relationship with tick bites, atopy, and cat ownership. Clin Exp Allergy 2014;44:1061-8

30. Fischer J, Biedermann T. Verzögerte Soforttypallergie gegenüber rotem Fleisch und Innereien. Aktueller Wissensstand zu einem neuen Krankheitsbild. J Dtsch Dermatol Ges 2016;14:38-44 